\title{
Unusual pattern in haemoglobin electrophoresis in Croatian population: a case report
}

\author{
Dragana Segulja*1, Danica Matisic ${ }^{1}$, Lorena Honovic ${ }^{3}$, Josip Batinic ${ }^{2}$, Dunja Rogic ${ }^{1}$ \\ ${ }^{1}$ University Hospital Centre Zagreb, Department of Laboratory Diagnostics, Zagreb, Croatia \\ 2University Hospital Centre Zagreb, Department of Internal Medicine, Zagreb, Croatia \\ ${ }^{3}$ General Hospital Pula, Laboratory of Clinical Chemistry, Pula, Croatia \\ *Corresponding author: dragana.segulja@gmail.com
}

\begin{abstract}
Haemoglobinopathies are hereditary disorders of globin chain synthesis and are the most common inherited diseases worldwide. Haemoglobin $\mathrm{E}$ is a structural haemoglobin variant characteristic for South East Asian population. We present a rare and unusual finding of haemoglobin E detected in University Hospital Centre Zagreb by capillary zone electrophoresis. Detection of haemoglobin structural variant helped to avoid misdiagnosis of sideropenic anemia and thus potentially harmful therapeutic intervention. In today's European multiethnic population haemoglobinopathies are a public health issue and Croatian laboratory professionals should be aware of a possibility of finding an unusual haemoglobin pattern.
\end{abstract}

Key words: HbE; haemoglobinopathies; capillary zone electrophoresis

\section{Introduction}

Haemoglobinopathies are hereditary disorders of globin chain synthesis. Depending on defect in haemoglobin synthesis, haemoglobinopathies can be divided into quantitative disorders (thalassemias), characterized by deficient synthesis of normal haemoglobin, or qualitative disorders which are characterized by the presence of structural variants of haemoglobin. Haemoglobinopathies, however, in most medical literature refer only to structural variants of haemoglobin. Haemoglobinopathies are also considered a hereditary persistent fetal haemoglobin synthesis, which is a disorder caused by failure in transition of the synthesis of fetal haemoglobin in adults. The gene prevalence of approximately $3 \%$ makes haemoglobinopathies the most common inherited diseases worldwide $(1,2)$.

Haemoglobinopathy is suspected in patients with hypochromia and/or anaemia after exclusion of iron deficiency, chronic haemolytic anaemia, druginduced anaemia, vascular occlusive crises of unknown etiology (in patients from areas with high haemoglobin S $(\mathrm{HbS})$ / haemoglobin $\mathrm{C}(\mathrm{HbC})$ prevalence), polycythaemia or cyanosis. Haemoglobin E heterozygotes ( $\mathrm{HbAE}$ ) are usually asymptomatic with mild hypochromia and microcytosis, with or without anaemia. Haemoglobin E homozygotes (HbEE) have moderate microcytic hypochromic anaemia with possible haemolysis due to exogenous causes (viral infections, drugs, malignant lymphadenopathy, connective tissue disease) (3).

Haemoglobin $\mathrm{E}(\mathrm{HbE})$ is a structural haemoglobin variant characteristic for South East Asian population. The highest frequencies have been observed in Thailand, Laos and Cambodia (4). HbE is characterized by the substitution of glutamic acid to lysine at position 26 in beta-globin chain. Several different laboratory methods are available to evaluate types of haemoglobin. Some of these methods include haemoglobin solubility test, electrophoresis, isoelectric focusing and high performance liquid chromatography (HPLC). The methods evaluate different types of haemoglobin based on the physical and chemical properties of 
different haemoglobin molecules. Amino acid replacement in globin chain changes the overall charge of the haemoglobin molecule and allows detection of haemoglobin variant by capillary zone electrophoresis (CZE). CZE is a powerful separation technique whose resolution is comparable to that of HPLC (5-7). Separation of haemoglobins by CZE is based on electroosmotic flow at an alkaline $\mathrm{pH} 9.4$ and high voltage of $9600 \mathrm{~V}$. Haemoglobins are detected at cathodic capillary end by absorbance measurements at $415 \mathrm{~nm}(8,9)$. Molecular techniques, based on polymerase chain reaction (PCR), can be used to confirm and define the mutation in haemoglobin genes.

The aim of this case report is to present haemoglobin electrophoresis pattern in a one-year-old girl as a rare and unusual finding detected in University Hospital Centre Zagreb. University Hospital Centre Zagreb is the largest and highest-categorized hospital in Croatia as well as a unique institution regarding many medical procedures, diagnostic methods and highly differentiated therapeutic procedures. With this case report, the authors would like to raise attention of clinical laboratory professionals to possibilities of encounter- ing unusual findings, characteristic for a specific geographical area.

\section{Clinical findings}

In Croatia, regular infant check-up by paediatrician at the age of six months includes blood cell count which is, if necessary, repeated at the age of one year. During the second check-up, blood cell count for a one-year-old girl was done on the Sysmex analyzer (Sysmex, Kobe, Japan). All parameters were within reference intervals except MCV $69.1 \mathrm{fL}$ and MCH $23.2 \mathrm{pg}$ (Table 1). According to the established laboratory procedure, it was not necessary to check RBC morphology in peripheral blood smear. Blood cell count was repeated one month later when the child had urinary infection. After antibiotic therapy, WBC and CRP were monitored. Ferritin was measured because of permanent hypochromia and microcytosis. CRP and ferritin were measured by standard immunoturbidimetric method on Cobas 6000 analyser (Roche Diagnostics, Basel, Switzerland). Negative result of blood stool test, considered together with medical history data, prompted us to perform haemoglobin electrophoresis.

TABLE 1. Laboratory results in index patient

\begin{tabular}{|c|c|c|c|c|c|}
\hline \multirow[b]{2}{*}{ Parameter } & \multicolumn{5}{|c|}{ Laboratory results in the one-year-old patient } \\
\hline & $\begin{array}{c}\text { Reference } \\
\text { interval }\end{array}$ & $\begin{array}{l}\text { Regular control in } \\
\text { the one-year-old girl }\end{array}$ & $\begin{array}{l}\text { One month after } \\
\text { regular control, } \\
\text { urinary infection }\end{array}$ & $\begin{array}{c}\text { After antibiotic } \\
\text { therapy }\end{array}$ & $\begin{array}{c}\text { Other } \\
\text { laboratory } \\
\text { tests }\end{array}$ \\
\hline White blood cells (x109/L) & $6.0-16.0$ & 12.4 & $17.9^{*}$ & 12 & / \\
\hline Red blood cells (x10 $12 / L)$ & $4.00-5.00$ & 4.75 & $3.77^{*}$ & 4.03 & / \\
\hline Hemoglobin (g/L) & $109-138$ & 110 & $86^{*}$ & $89 *$ & / \\
\hline MCV (fL) & $73.8-89.4$ & $69.1^{*}$ & $68.2^{*}$ & $68.8^{*}$ & / \\
\hline MCH (pg) & $24.3-29.2$ & $23.2^{*}$ & $22.8^{*}$ & $22.2^{*}$ & / \\
\hline Platelets (x109/L) & $150-450$ & 398 & $519 *$ & $927^{*}$ & / \\
\hline CRP (mg/L) & $0.1-2.8$ & / & $39.4^{*}$ & 0.5 & / \\
\hline Urine sediment & l & normal & $\begin{array}{l}\text { leukocyturia, } \\
\text { bacteriuria* }\end{array}$ & normal & l \\
\hline Blood stool test & l & l & / & l & negative \\
\hline $\mathrm{Fe}(\mu \mathrm{mol} / \mathrm{L})$ & $4-25$ & 15.1 & / & / & 4 \\
\hline Ferritin $(\mu g / L)$ & $7-142$ & / & / & / & 128.8 \\
\hline
\end{tabular}

Reference intervals are harmonized intervals recommended by Croatian Chamber of Medical Biochemists (20). * Results outside the reference interval. "I" - not performed. 




Figure 1. Hemoglobin electropherogram pattern in index patient.

\section{Diagnostic focus and assessment}

Haemoglobin electrophoresis was done according to manufacturer's instructions using automated system Capillarys 2 (Sebia, Lisses, France). The sample was whole blood taken on EDTA anticoagulant. After manual preparation of washed erythrocytes, haemolysate was prepared using an automated protocol on instrument Capillarys 2. The obtained pattern of haemoglobin electrophoresis indicated the presence of abnormal haemoglobin (Figure 1). By comparing patient electropherogram with electropherogram of most common haemoglobin variants $(A, A 2, F, S, C)$, it was found that none of those variants were present in the sample (Figure 2) $(3,8)$. According to software support (Capillarys Hemoglobin, software version 6.1.2), HbE, HbKoln and $\mathrm{HbA} 2$ variants could be detected in zone $\mathrm{Z4}$. It was necessary to find out whether $\mathrm{HbE}$ is the next most common haemoglobin variant, what geographic area it is characteristic for, and where our patient and her parents come from $(2,4,5,7,8)$.

The proportion of suspected $\mathrm{HbE}$ in our one-yearold patient was $24.5 \%$ (Figure 1). According to literature, it is characteristic for the $\mathrm{HbE}$ proportion in $\mathrm{HbE}$ heterozygotes to be 25 - $35 \%$ (2). HbE homozygotes have a high RBC count, MCH 20 pg, MCV $65 \mathrm{fL}$, and haemoglobin electrophoresis with the haemoglobin proportions: $\mathrm{HbE}>95 \%, \mathrm{HbA} 2$ $=2.5 \%, \mathrm{HbF}<3 \%(2)$.
However, in order to confirm our suspicion, we requested family history data and parents' blood samples. Before analysing parents' blood samples, their informed consent was obtained. The mother is originally from Thailand and has mild anaemia (Table 2) and similar haemoglobin electrophoresis pattern as the child (Figure 3). Two of them are probably $\mathrm{HbE}$ heterozygotes. The father is from Croatia and has expected pattern of haemoglobin electrophoresis (Figure 4).

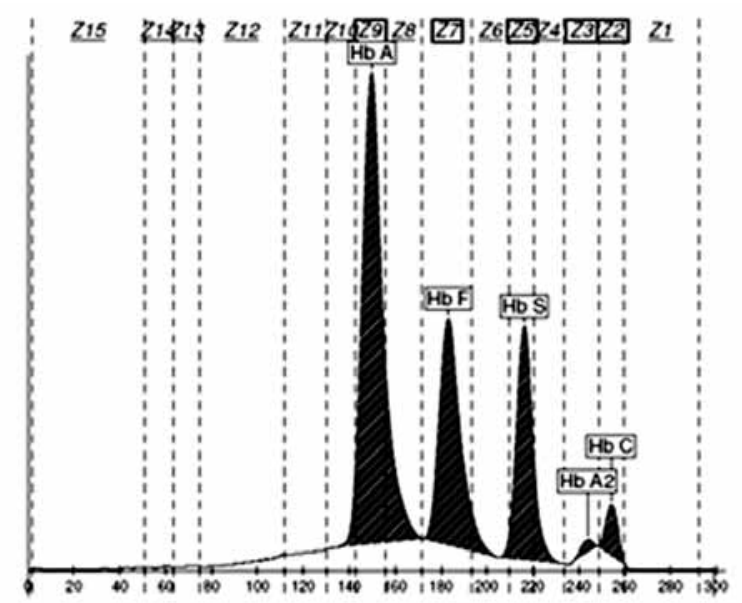

Figure 2. Haemoglobin electropherogram with the most common haemoglobin variants in European population $(\mathrm{Hb} \mathrm{A}, \mathrm{Hb}$ $\mathrm{F}, \mathrm{Hb} \mathrm{S}, \mathrm{Hb} \mathrm{A} 2, \mathrm{Hb} \mathrm{C}$ ) - control sample, Hb AFSC Control (Sebia, Lisses, France) 
TABLE 2. Laboratory results in patient's parents

\begin{tabular}{lcccc}
\hline \multirow{2}{*}{ Parameter } & \multicolumn{2}{c}{ Mother's laboratory results } & \multicolumn{2}{c}{ Father's laboratory results } \\
\cline { 2 - 5 } & Reference interval & Results & Reference interval & Results \\
\hline White blood cells (x109/L) & $3.4-9.7$ & 8.9 & $3.4-9.7$ & 8.6 \\
Red blood cells (x1012/L) & $3.86-5.08$ & 4.68 & $4.34-5.72$ & 5.1 \\
Haemoglobin (g/L) & $119-157$ & $116^{*}$ & $138-175$ & 159 \\
MCV (fL) & $83.0-97.2$ & $75.5^{*}$ & $83.0-97.2$ & 93.6 \\
MCH (pg) & $27.4-33.9$ & $24.8^{*}$ & $27.4-33.9$ & 31.2 \\
Platelets (x109/L) & $158-424$ & $439^{*}$ & $158-424$ & 284 \\
\hline
\end{tabular}

Reference intervals are harmonized intervals recommended by Croatian Chamber of Medical Biochemists (20). ${ }^{*}$ Results outside the reference interval.

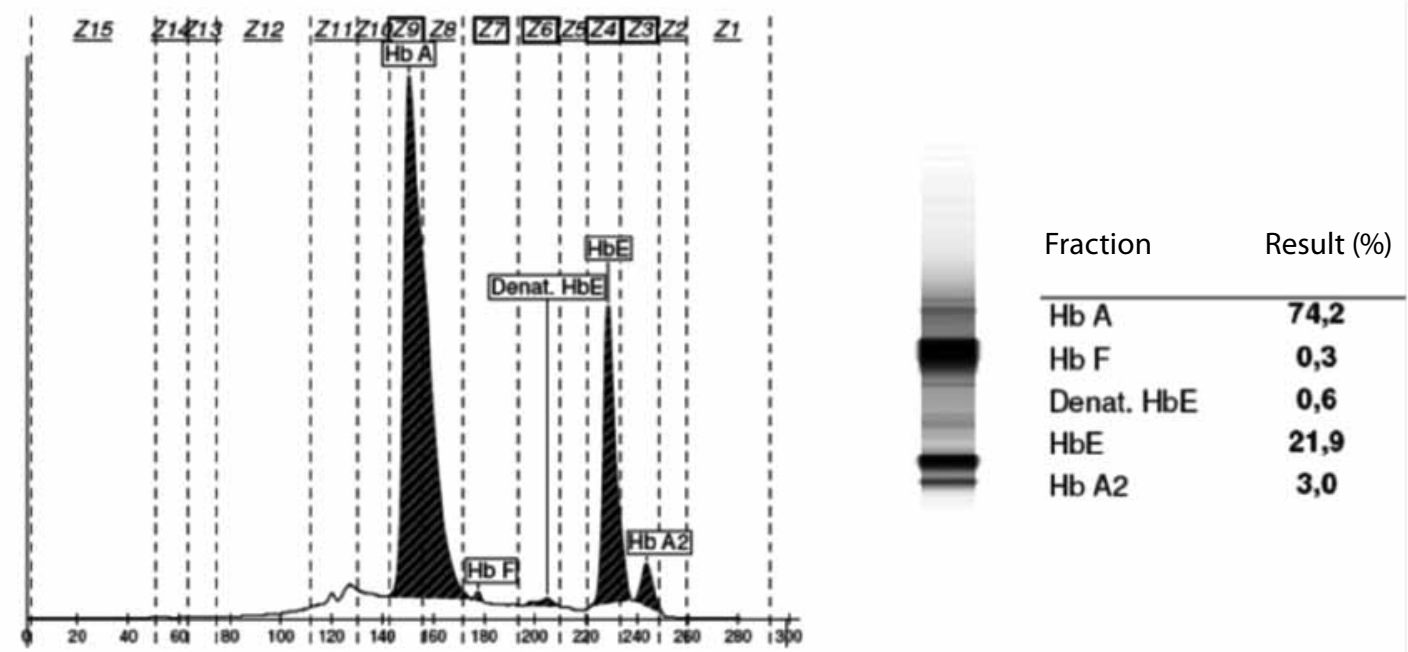

FIGURE 3. Mother's haemoglobin electropherogram. Characteristic finding in HbE heterozygotes is approximately as follows: $25-35 \%$ $\mathrm{HbE}, 1 \% \mathrm{HbF}, 70-75 \% \mathrm{HbA}$.

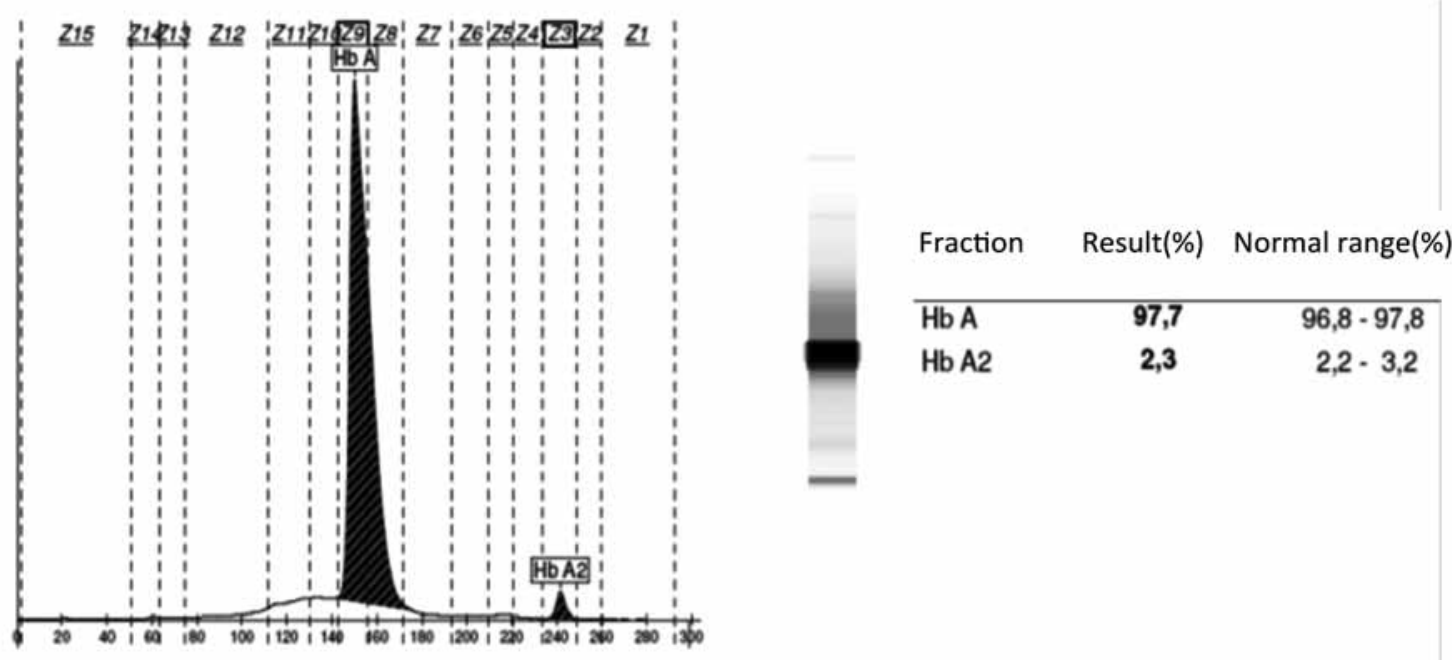

FIGURE 4. Father's haemoglobin electropherogram - expected haemoglobin pattern in most European (including Croatian) populations. 
Thanks to indirect collaboration with Hospital Delafontaine (Saint-Denis, Paris, France), patient sample was analysed on the same type of instrument (Capillarys 2) but using another electrophoresis protocol, the one for $\mathrm{HbA}_{1 \mathrm{c}}$ (Sebia, Lisses, France). The result indicated presence of haemoglobin molecule, with proportion of $23 \%$ of total haemoglobin, in the migration zone characteristic for $\mathrm{HbE}$. In addition, high performance liquid chromatography (HPLC) on Variant II system (Bio Rad, Hercules, California) was performed in the same institution and the results indicated $28 \%$ of $\mathrm{HbE}$.

\section{Discussion}

Similarity in haemoglobin electrophoresis patterns and the position of unusual peak support the assumption that the index patient inherited $\mathrm{HbE}$ variant from her mother. The same refers to erythrocyte indices which indicate heterozygous presence that can be confirmed only by molecular techniques. Although molecular analysis has not been done, due to excellent resolution and reproducibility of CZE and other conducted reliable tests, it was indicative that the atypical haemoglobin variant corresponds to $\mathrm{HbE}(10,11)$. CZE was demonstrated to be comparable to HPLC in detection of $\mathrm{HbE}$ variant but both used techniques are still considered very powerful screening techniques.

Since Chernoff and his colleagues in 1954 first described $\mathrm{HbE}$, it was increasingly reported from several parts of the world (12). HbE has been associated with a survival advantage against Plasmodium falciparum and that could be the logical explanation for its geographic distribution (13). Migrations in past decades led to its findings in the United States and Canada (14). In 2012 Cataldo wrote about changes in the epidemiology of haemoglobin disorders in Italy as a result of immigration (15).
In this regard, Croatia is no exception. World Health Organisation recognised haemoglobinopathies as public health problem and from 2008 recommends screening and genetic counselling for haemoglobin disorders as an intrinsic part of health care in most countries (16).

Although the presence of $\mathrm{HbE}$, except for microcytic and hypochromic anaemia, does not cause significant clinical symptoms, it is important to identify this haemoglobin variant and exclude sideropenic anaemia $(17,18)$. Iron supplements are contraindicated in patients with $\mathrm{HbE}$ since their consumption can lead to iron accumulation in tissues and furthermore end organ failure may not be suspected because the serum ferritin level is disproportionately low (19).

\section{Conclusion}

Reliable detection of $\mathrm{HbE}$ variant was performed using CZE and HPLC. Although $\mathrm{HbE}$ variant is an endemic related to areas affected by malaria, our finding suggests that heterozygotes can be found anywhere in the world. Detection of $\mathrm{HbE}$ for the first time in last 30 years in our institution may indicate increasing migration of population and a possibility of finding haemoglobin variants which were previously associated only to a specific geographic area. In this regard, laboratory professionals should always be aware of a possibility of finding an unusual haemoglobin pattern in "non-typical" areas. In addition, knowing the parents' origin helped us to suspect the presence of $\mathrm{HbE}$ in a oneyear-old girl. This crucial information was received from a clinician, confirming that geographic affiliation is valuable information in interpretation of haemoglobin electrophoresis results.

\section{Potential conflict of interest}

None declared. 


\section{References}

1. Kohne E. Hemoglobinopathies. In: Thomas L, ed. Clinical laboratory diagnostics: Use and assessment of clinical laboratory results. 1st ed. Frankfurt/Main: TH-Books-VerlaggeseIlschaft;1998. p. 486-493.

2. Kutlar A. Laboratory diagnosis of the hemoglobinopathies. Available at: http://www.uptodate.com/contents/laboratory-diagnosis-of-the-hemoglobinopathies. Accessed April 17th 2016.

3. Kohne E. Hemoglobinopathies: clinical manifestations, diagnosis, and treatment. Dtsch Arztebl Int 2011;108:532-40.

4. Fucharoen S, Winichagoon P. Haemoglobinopathies in Southeast Asia. Indian J Med Res 2011;134:498-506

5. Keren DF, Hedstrom D, Gulbranson R, Ou CN, Bak R. Comparison of Sebia Capillarys electrophoresis with the Primus high-pressure liquid chromatography in the evaluation of hemoglobinopathies. Am J Clin Pathol 2008;130:824-31. http://dx.doi.org/10.1309/AJCPQY80HZWHHGZF.

6. Jenkins MA, Hendy J, Smith IL. Evaluation of hemoglobin A2 quantification assay and hemoglobin variant screening by capillary electrophoresis. J Capillary Electrophor 1997;4:137-43.

7. Altinier S, Varagnolo M, Zaninotto M, Plebani M. Identification and quantification of hemoglobins in whole blood: the analytical and organizational aspects of Capillarys2 Flex Piercing compared with agarose electrophoresis and HPLC methods. Clin Chem Lab Med 2013;51:791-7. http://dx.doi. org/10.1515/cclm-2012-0061.

8. Amato A, Giordano PC. Screening and genetic diagnosis of hemoglobinopathies in Southern and Northern Europe: two examples. Mediterr J Hematol Infect Dis 2009;1:e2009007. http://dx.doi.org/10.4084/mjhid.2009.007.

9. Matišić D. [Primjena automatiziranih elektroforetskih metoda visoke djelotvornosti u kliničkom laboratoriju]. In: [Elektroforeza hemoglobina kapilarnom zonskom elektroforezom], Matišić D, ed. Zagreb: Medicinska naklada; 2011. (in Croatian)

10. Mais DD, Gulbrason RD, Keren DF. The range of Hemoglobin A2 in Hemoglobin E heterozygotes as determined by capiIlary electrophoresis. Am J Clin Pathol 2009;132:34-8. http:// dx.doi.org/10.1309/AJCPP50JIXXZVLSS.
11. Hafiza A, Malisa MY, Khirotdin RDA, Azlin I, Azma RZ, Thong $M C K$ et al. HbA2 levels in normal, beta-thalassaemia and haemoglobin E carriers by capillary electrophoresis. Malaysian J Pathol 2012:34:161-4.

12. Moiz B, Hashimi MR, Nasir A, Rashid A, Moatter T. Hemoglobin Esyndromes in Pakistani population. BCM Blood Disord 2012;12:3. http://dx.doi.org/10.1186/1471-2326-12-3.

13. Chotivanich $K$, Udomsangpetch $R$, Pattanapanyasat $K$, Chierakul W, Simpson J, Looareesuwan S, White N. Hemoglobin E: a balanced polymorphism protective against high parasitemias and thus severe $P$ falciparum malaria. Blood 2002;100:1172-6.

14. Lachant NA. Hemoglobin E: an emerging hemoglobinopathy in the United States. Am J Hematol 1987;25:449-62. http://dx.doi.org/10.1002/ajh.2830250411.

15. Cataldo F. Immigration and changes in the epidemiology of hemoglobin disorders in Italy: an emerging public health burden. Ital J Pediatr 2012;38:32. http://dx.doi. org/10.1186/1824-7288-38-32.

16. Modell B, Darlison M. Global epidemiology of haemoglobin disorders and derived service indicators. Available at http:// www.who.int/bulletin/volumes/86/6/06-036673/en/. Accessed September 4th 2016.

17. Olivieri NF, Pakbaz Z, Vichinsky E. Hb E/beta-thalassaemia: a common and clinically diverse disorder. Indian J Med Res 2011;134:522-31.

18. Northrop-Clewes C, Thurnham DI. Biomarkers for the differentiation of anemia and their clinical usefulness. J Blood Med 2013;4:11-22.

19. Pakbaz Z, Fischer $R$, Fung E, Nielsen P, Harmatz P, Vichinsky E. Serum ferritin underestimates liver iron concentration in transfusion independent thalassemia patients as compared to regularly transfused thalassemia and sickle cell patients. Pediatr Blood Cancer 2007;49:329- 32. http://dx.doi. org/10.1002/pbc.21275.

20. Stavljenić Rukavina A, Čvorišćec D, eds. [Harmonizacija laboratorijskih nalaza u području opće, specijalne i visokodiferentne medicinske biokemije]. Zagreb: Medicinska naklada;2007. (in Croatian) 